\title{
On nature, culture and sustainable design
}

\author{
A. Yates \\ Massey University, Wellington, New Zealand
}

\begin{abstract}
Sustainable design is a complex and elusive thing to define, to design, to measure. A fully sustainable architecture would be one constructed within a fully sustainable culture, a culture within which all inputs and outputs are considered, designed. To move to a sustainable design and building practice in Western culture requires a major paradigm shift: it requires that we rethink our cultural habits from first principles; that we re-conceive the very notion of what buildings and cities are, rethinking them as generative, as active sites of production rather than as inert objects. This requires a re-location from traditional Western notions of building as permanent and static, towards building as organism, plant or landscape, as active and regenerative agent changing under inhabitation and in response to diurnal and seasonal shifts. Such a move requires a destabilising of the Western model of separate disciplines of urban design, architecture, landscape architecture, and interior design in favour of modes of thinking and making which move fluidly across all of these contiguous disciplinary territories.

This paper explores Western and Oceanic notions of culture and nature, it tracks how cultural understandings are made manifest within built fabric. In doing so the paper offers an opportunity to rethink dominant Western models of space making, to move into a field of theorised practice in which culture and nature, building and landscape are interspersed and contiguous. Such architectural landscapes offer the potential to be regenerative habitats, artificial landscapes that generate food and energy; collect and filter water; remediate waste into new resources; offer native habitat to local fauna and flora; and create interior habitats that are strongly connected to the natural environment.
\end{abstract}

Keywords: regenerative design, Indigenous design, nature, architecture. 


\section{Introduction}

Sustainable design is a complex and elusive thing to define, to design, to measure. A fully sustainable architecture would be one constructed within a fully sustainable culture, a culture within which all inputs and outputs are considered, designed. To move to a sustainable design and building practice in western culture requires a major paradigm shift: it requires that we rethink our cultural habits from first principles, that we look outside the dominant culture to other ways of thinking of the relationship between nature and culture; that we look to other cultures' spatial practices; that we re-conceive the very notion of what buildings and cities are, rethinking them as generative, as active sites of production rather than as inert objects.

This paper suggests that we must reconsider Western culture's deepest assumptions about the relationship between nature and culture in order to provide a stable ground for sustainable cultural production. Such a thesis may seem, at first glance, to be somewhat ingenuous or unrealistic for it is easy to assume that it is economic factors which are the primary drivers for the, largely, unsustainable nature of Western cultural outputs. There are, however, many cultural inertias which underpin our cultural assumptions, our design assumptions, our legislation, our politics, our practices, which drive our outputs and therefore our economies. There are numerous examples in which a cheaper and more environmentally sustainable solution is not sought because of government subsidies for a more environmentally destructive option; because an item is not widely culturally accepted, or 'fashionable'; or because of a culturewide lack of systematic and integrated sustainable thinking and planning. It is clear, from the companies that have done so, that there are significant gains to be made in switching from what are usually waste generating, open loop unsustainable systems, to more sustainable zero-waste, closed loop systems. Such gains can be measured in savings from pollution remittance measures, health care costs, material and resource costs, waste management, and energy generation, as well as in the preservation of natural habitat.

To a large degree these problems, and their solutions, are design issues, they are issues to do with our current design paradigms. If we are to become a sustainable culture we will need to shift the paradigm of our design thinking towards sustainable and regenerative solutions that are integrated across our culture's outputs. These terms, sustainability and regenerative design, are subject to a range of different interpretations. In this paper 'sustainability' is used to describe conditions that enable life to develop and evolve; the term regenerative design is used in the sense that Bill Reed describes it, as not being simply about "making a landscape and local habitat more productive and healthy. Effective regeneration requires that we engage the entirety of what makes a place healthy - the core interrelationships between earth systems, humans and the consciousness or spirit that connects them." [1].

In order to radicalise our current practice we need to understand the cultural subtexts that drive our design practice; we need to understand what our most basic assumptions are about the environment that we inhabit, that we modify 
through our activities. This paper, therefore, begins with an exploration of what nature and culture are understood to be. Western traditions are analysed, alongside Oceanic notions and practices. In paralleling the two the intent is not to reify or privilege indigenous culture or cultural practices, as the West has some history of doing [2] or to revert to a romanticism in which the indigenous other is identified with nature. Rather the paper aims to move between cultures with a view to disrupt assumptions within, and gather strategies for, contemporary sustainable and regenerative design.

Following this Oceanic building practices are explored in relation to their potential for contemporary sustainable design development. Particular attention is paid to the manner in which Pacific spatial practices problematise Western notions of architectural enclosure, interiority and landscape. Inhabited architectural landscapes make evident a paradigm within which the earth itself is used as a spatial matrix, merging interior and exterior, creating contiguous landscape habitats. Oceanic porous textile walls challenge architectural enclosure and notions of interiority, they form space that exists as both interior and exterior.

Finally, in order to establish strategies for sustainable and regenerative spatial design, this paper suggests a re-location from traditional Western notions of building as permanent and static, towards a concept of building as organism, plant or landscape. Built habitats then are conceived as networked, active and regenerative agents changing under inhabitation and in response to diurnal and seasonal shifts. Such a move requires a destabilising of the Western model of separate disciplines of urban design, architecture, landscape architecture, interior design in favour of modes of thinking and making which move fluidly across all of these contiguous disciplinary territories.

\section{Nature and culture}

There has been some two hundred years of contact now between the West and Oceania, in which period there has been a mingling of cultural beliefs. Yet it is possible to identify quite different attitudes to the nature-culture relation via language, mythologies and material practices, as well as via Western historical studies. The Western nature/culture binary is not evident within Pacific mythologies and practices, rather the relation may best be described as a continuum.

The term 'nature' derives from the Latin natura, or what a thing is, its character or essence. Natura derives from the Greek phusis, a term whose meaning developed to encompass 'everything'; in this usage there can be 'nothing that is not "nature" - it has no opposite' [3]. Over time however this expansive definition reduced to the point where 'nature' is now commonly understood as 'the world apart from human influence' [4]. This cultural construction is influenced by Aristotelian philosophy, and a Christian tradition in which 'God is regarded as the creator of nature, meaning that nature in this demoted sense is distinct from God, but also that He is related to it as a creator or artisan is to a piece of work, or as a master to a servant.' [5]. Nature and 
culture, in this tradition, may be described as a binary pairing within which relative status has shifted over time. In the current formulation of this pairing nature is subordinate to culture; culture is active, it is creative, it is human generated; nature is that which is not human, it is lacking in agency.

This notion of a nature/culture binary is a cultural construction that has had particular currency in Western thought over the last 200 years; rather than being universal it is specific to that cultural tradition. A range of disciplines, including environmental, post-colonial and cultural studies, have begun to extend or review this construct. Cultural theorist Elizabeth Grosz' work has been concerned, for some years now, with rethinking the relationship between nature and culture. She writes that:

'Cultural studies seem founded on the supposition of an immense, unhealable rift between the human and the rest of organic life: the human is unique, immersed in language, denaturalised through cultural and technological extension and augmentation, and thus stands outside of the natural order. But what if, as Darwin suggests, all the characteristics that we posit as uniquely human - reason, language, emotions, cultural associations, the use of tools and technologies, and so on - are simply differences of degree from the animal rather than a difference in kind? What if, instead of a rift, there is a continuity between the human and the animal?... How can the study of culture acknowledge its embeddedness in nature...' [6].

Grosz argues for a reconsideration of the nature/culture binary in order to invigorate our thinking. Rather than the either/or relationship she posits that the two are mutually engaged. Grosz suggests that:

'It may be inaccurate to regard nature and culture as two mutually exclusive and mutually exhaustive categories, that is, as binarized or oppositional terms in which one takes on the right to define the other as its negation or deprivation; this is to regard them as contained categories, each of which has given boundaries and no space of overlap. Instead it may prove fruitful to understand them as terms whose relation is defined by emergence. Nature is the ground, the condition or field in which culture erupts or emerges as a supervening quality not contained in nature but derived from it.' [7].

A similar repositioning of the idea of nature, and its relationship to culture, is apparent in the work of some Western trained ecologists challenging the dominant Western model of conservation in which humans are seen as separate from nature. In contrast to this ecologist and writer Geoff Park asserts that in the 'elemental terms of matter and energy, people ultimately are land, no more, no less than the birds, insects, trees and seeds and the constant process of their birth, growth and decay and the movement of them and their parts through the landscape.' [8]. Such a view mirrors Oceanic traditions of the relationship between human and nature. The term whenua describes both placenta and land; these meanings overlay and profoundly intersperse; the term signifies the inseparable interaction and contiguity of the natural environment and humanity. Whenua and 'words like whenua - fenua, fonua, fanua - and with similar meaning, can be heard in Tahiti, Samoa and Tonga respectively; wherever in the Pacific that Polynesian cultures reached. But whenua's roots are far older than 
anything Polynesian. An ancient Austronesian concept from when people first entered the south-west Pacific, whenua shares linguistic roots with the vanua of Fiji and the banua of Bali, both conceptualisations of identity in which the historical relationship between human beings and the land is vital.' [9].

In Maori [New Zealand indigenous] origin narratives the land is body, that of Papatuanuku, humans are the grand-children of that body and the sky father, Ranginui. This narrative establishes humans as descendants of the natural order, a radically different position to that understood within the Judeo-Christian tradition. There is, in this Pacific world-view, a sense of connection rather than separation, a nature-culture continuum. Such a world-view does not reduce the struggle to balance resource extraction against growth imperatives, but it does site that struggle within an awareness that we are formed from, and are part of the natural environment. This paper posits that such an awareness is crucial to the development of a sustainable and regenerative contemporary spatial practice.

\section{Oceanic practice: architectural landscapes and porous spatial boundaries}

A nature-culture continuum is apparent within the Oceanic spatial paradigm. Oceanic built space may be characterised as fluid, both spatially and in terms of Western spatial disciplines. In Western practice urban design, architecture, landscape architecture, and interior design are understood as distinct and separate disciplines with the boundaries between, both spatial and disciplinary, strictly maintained. Architecture has a certain primacy over the interior and landscape, a concern with structure, form and function, with durability, monumentality or temporal stasis. A primary propriety for architecture is to be weather-proof, to resist water in all its forms. The architectural boundary therefore must be stable, weather-tight, it must police the frontier between interior and exterior. The interior design discipline tends to be characterised as the lesser of the binary opposition, architecture and interior design, positioned as the temporal and temporary, against architecture's supposed permanence. Landscape architecture is also figured as sub-ordinate to architecture's concern with enclosure. Urban design is separate again, separated in part by architecture's insistence on bounded objects. Spatial theorists Bill McKay and Antonia Walmsley, in their paper on Pacific space, discuss these Western disciplines, they:

'explore the extent to which buildings of the Pacific subvert this Western model... What if these indigenous structures are not architecture and have more of an affinity with the crafts such as weaving, binding, carving and painting? What if these buildings are closer to clothing or furniture or even floral arrangement than they are to building? What if the buildings of Oceania are not so much a topic for architectural history as one for the disciplines of landscape and interior design?' [10].

Oceanic spatial constructs operate in a conceptual and material field of fluid boundaries which problematise notions of 'interior', 'exterior' and conceptions of 'contained' space; these operate, as McKay and Walmsley suggest, outside of the Western model. Architectural critic Mike Austin writes that 'Pacific 
architecture can be argued to be another set of formal paradigms involving the architecture of openness... the platform (marae) and the pavilion (the fale, whare, bure, etc)' [11]. This paradigm of openness can be understood as an architecture of landscape, the ground-based platform, and an architecture of radicalised interiority, the pavilion. This paper will explore these two aspects of Oceanic building practice.

McKay and Walmsley's suggested repositioning of Oceanic buildings within the disciplinary zones of landscape and interior design is particularly appropriate when one considers the Oceanic tradition of architectural landscapes. In this practice the ground itself is worked to form inhabited space and to service inhabitation. This 'landscaping' tradition is apparent at the micro-scale, where the earth is used as a vessel, a contained 'interior', within which to cook or store food, and at the macro-scale, in monumental architectural landscapes which operate as large-scale inhabitations or fortifications.

New Zealand offers a uniquely rich site for the investigation of Oceanic monumental landscapes. Archaeologist Ian Barber writes that while '[monumental paa] structures are probably underreported for many Pacific Island landscapes (S.Best 1993:438-39), there is still no question that the number of Maaori paa is without precedent in Polynesia... Given the sociopolitical and ceremonial importance of paa, such landscapes represent spectacular and enduring visual re-creations of border, order, identity, and ancestry.' [12]. Throughout New Zealand the land bears imprints from such interventions as the terracing of pa [indigenous architectural landscapes] to form defensible, habitable zones; the recessing of kumara pits to form storage vessels within the ground; the indenting of fire pits; and the imprinting of the sunken interiors of whare [indigenous houses]. A coherent and networked built landscape is generated through this use of the earth itself as structure, as a building material, as a generator of interior space.

In Loss, Change and Monumental Landscaping Ian Barber discusses the overuse and subsequent failure of a primary food resource in relation to pa construction finding that [Given] a resource-crisis concern for territoriality, control, and permanence, paa of the fifteenth and sixteenth centuries at least may represent a monumental reaffirmation of and appeal for the extension of a more beneficent and productive order into a now more permanently capricious island world... In its symbolism, the paa landscape ... united expressions of 'cultural' landscaping with 'natural' sacred ancestral [land] ... paa building extended and reintegrated the traditional landscape... a response of spiritual continuity and connectivity to stressful environmental change' [13]. There is, in this theory, a complex layering of culture and nature in order to formulate sustainable economies and ecologies; a culture-nature continuum established by ritualised landscape-building practices.

Pacific 'pavilions' operate in contrast to these monumental landscapes. Architectural theorist Sarah Treadwell describes these as being permeable, flexible and responsive, 'premised on mobility, lightly fabricated and impermanent' [14]. These structures tend to the temporary and the porous, constructed as they are from layered or woven organic materials that form semi- 
permeable screens. Some wall screens are operable, able to be raised to take advantage of winds; others are designed to fail under cyclones, subsequent to which they are rebuilt; all require an ongoing process of recycling and reworking to maintain their integrity. Such temporal, temporary and partially enclosed structures offer an alternative model for contemporary spatial design, suggesting space that is engaged and activated through inhabitation and responsiveness to the environment.

Both the architectural landscapes and the porous 'pavilions' are constructed from materials that are 'native' to their site. The architectural landscapes are durable, but formed as they are from the ground, erode over time, leaving no toxic residue. The organic material from which the porous 'pavilions' are formed rots down to form valuable resource for the local eco-system. Both have fluid boundary conditions in which exterior and interior are blurred and multiple; here nature and culture are not constructed as separate conditions, but rather are interspersed and contiguous. This spatial paradigm forms as a kind of inhabited landscape, a nature-culture hybrid that has potential as a model for a regenerative contemporary design practice.

\section{Sustainable design strategies: regenerative architectural landscapes.}

Sustainable design is an immensely difficult thing to define or to frame. It is continually elusive, in part because we lack the metrics to enable a true measure of our effect on the planet; in part because we lack a reliable and definitive account of what balance we need to maintain in order to survive; in part because we disagree about who or what should take precedence in the environment. It is certainly made more difficult by a Western cultural perception that we are separate from nature. Such a view has led to our current culture of waste, a belief that we can throw our cast-offs away to a separate 'nature'. It has led to a design culture that lacks the mutability, the extreme resourcefulness and networked responsiveness apparent within natural systems. Given that we are 'exceeding the carrying capacity of natural systems by a factor of ... six in the West' [15] it is clear that we cannot continue to operate in this way. Restrictions and efficiencies will not be sufficient to address this polluting and consumptive cultural paradigm.

This paper suggests that in order to establish a reliably sustainable and regenerative culture we need to radically reconsider our cultural assumptions, redesigning our culture therefore from its founding concepts of nature and culture, establishing a new regenerative design paradigm. Oceanic spatial practice, with its cultural sub-text of a nature-culture continuum, its architectural landscapes and porous plant-based pavilions, offers rich ground upon which to develop contemporary regenerative design practices. It suggests space that operates as flora, as plant or as landscape; that is networked and inter-connected, both socially, and in terms of energy generation and transport modes; that is generative, of energy, food and potentially building materials; that is formed either of long-term durable or temporary but sustainably renewing material; that 
offers native habitat to local flora and fauna; that is responsive to the environment and to its inhabitants; and that offers its inhabitants a delightful fusion of natural habitat and fabricated enclosure. In such a paradigm the weather-tight architectural enclosure is ruptured, its hermetic membrane made porous and ephemeral; boundaries become defined through movement, passage, inhabitation; space is characterised by immanence rather than by stability. This spatial rupture generates a disciplinary rupture, a merging or becoming other; what was once architecture becomes something in-between architectural enclosure, interior and urban landscape.

Such a re-positioning enables a rethinking of the built environment as a continuum, an architectural landscape whose contiguous territories enable effective resource use, resource and energy generation, and inhabitation. The human race is now largely an urban species, our primary habitat the city. Rethinking the city from its current assemblage of singular architectural objects to an integrated networked architectural landscape allows a move from the disease prone monoculture of Western planning. It allows a shift to an integrated model, a mixed 'planting' of industry, domiciles, public and private spaces, 'landscape' zones and transport nodes. Such an urban architectural landscape would have generation as a basic operation: micro and macro generation of electricity; generation of food in 'garden' zones or pockets associated with domiciles; catchment and treatment of rainwater; treatment of sewage and green waste and up-cycling of other post-use items; generation of building materials, such as plant based plastics, and composite earth products.

This generative architectural landscape model could facilitate a move from our current unsustainable oil-based economy to a renewable electricity economy. Such synergies are a necessary part of a sustainable design model. Habitat generated energy could service homes, business, industry and private and public transport systems. Transport across such an urban landscape would be integrated such that walking and cycling are facilitated in combination with public and private transport systems. Inhabitation would be dense, to minimise urban sprawl and enhance connectivity, but densely integrated too with landscape elements.

Cities such as Curitiba, Brazil, offer an example of an integrated design model in which transport has been integrated into a city-wide system [16]. Architectural firm William McDonough and Partners currently have a mixed-use retail and residential 'sustainable' development under construction that includes roof gardens that act as site of production of food, power and recreation. At a much larger scale they are designing six new cities in China with the intent to develop landscaped cities that feature closed-loop systems that mine waste for resources, that generate energy, grow food and remediate the natural environment [17]. These proposed eco-cities may be understood as urban architectural landscapes given these qualities.

Associated with an urban architectural landscape model is the potential to radicalise our current spatial experience. This is particularly critical given that the human race 'now spends 80 percent of its time indoors - 60 years in a lifetime. The human habitat is essentially an interior' [18]. An architectural landscape model would allow for the development of 'interior' space that is 
mutable, adjustable, operable such that the exterior and natural environment can be engaged, dependent on environmental conditions. Such an urban design strategy would encourage interior-exterior space that is responsive to its inhabitants and to environmental conditions; such an urban habitat would blur the boundaries between 'nature' and 'culture', operating rather as an acculturated landscape, a culture-nature continuum.

\section{Conclusion}

This thesis explores Western and Oceanic notions of culture and nature, tracking the manner in which culture-nature relationships are made manifest through spatial practice. In so doing this exploration offers an opportunity to rethink dominant Western models of space making, to move into a field of theorised practice that is inflected by an indigenous practice in which culture and nature, building and landscape are interspersed and contiguous. The paper posits that we need to rethink and remake our buildings and cities as nature-culture continuums, as generative 'plants' networked in an architectural landscape that offers a delightful and sustainable habitat within which to live.

\section{References}

[1] Reed, B., Shifting Our Mental Model - "Sustainability" to Regeneration. Rethinking Sustainable Construction Conference 2006: Next Generation Green Buildings, 2006.

[2] Baudet, H., Paradise on Earth: Some thoughts on European Images of NonEuropean Man, Yale Uni Press: New Haven Conn, pp. 2, 1965.

[3] Evernden, N., The Social Creation of Nature, John Hopkins Press: Baltimore, pp. 19, 1992.

[4] Evernden, N., The Social Creation of Nature, John Hopkins Press: Baltimore, pp. 20, 1992.

[5] Evernden, N., The Social Creation of Nature, John Hopkins Press: Baltimore, pp. 21, 1992.

[6] Grosz, E., Time Travels: Feminism, Nature, Power. Duke University Press: Durham and London, pp. 49-50, 2005.

[7] Grosz, E., Time Travels: Feminism, Nature, Power. Duke University Press: Durham and London, pp. 44, 2005.

[8] Park, G., Theatre Country: Essays on Landscape and Whenua. Victoria University Press: Wellington, pp. 25, 2006.

[9] Park, G., Theatre Country: Essays on Landscape and Whenua. Victoria University Press: Wellington, pp. 25, 240-241, 2006.

[10] McKay, B \& Walmsley, A., Pacific Space: The Pacific Conception of Building. Idea Journal 2005, Queensland University of Technology: Brisbane 61-71, 2005.

[11] Austin, M., Kiwi Architecture: Modernism Recycled. Fabrications, 14, (1\&2), pp. 13-19, 2004. 
[12] Barber, I., Loss, change and monumental landscaping: towards a new interpretation of the "classic" maaori emergence. Current Anthropology, 37, (5), pp. 868-880, 1996.

[13] Barber, I., Loss, change and monumental landscaping: towards a new interpretation of the "classic" maaori emergence. Current Anthropology, 37, (5), pp. 868-880, 1996.

[14] Treadwell, S., Digital Weather: Pacific Space. In Eu Jin Chua and Miriam Bellard (Eds), Quickenings-Digital Film Architecture. The NZ Film Archive: Auckland, 2002.

[15] Edwards, B., Architectural Design, Vol 71, No 4, July, 19, pp. 22-23, 2001.

[16] Mau, B., Massive Change. Phaidon Press: London, pp. 58-61, 2004.

[17] Steffen, A., (Ed), Worldchanging: A Users Guide for the $21^{\text {st }}$ Century. Abrams: New York, pp. 275, 2006.

[18] Edwards, B., Architectural Design, Vol 71, No 4, July, 19, pp. 22-23, 2001. 